\title{
Formulation and Characterization of a Kinetically Stable Topical Nanoemulsion Containing the Whitening Agent Kojic Acid
}

\author{
Gan Yi Yun ${ }^{1}$, Nur Azzanizawaty Yahya ${ }^{1,2}$, Roswanira Abdul Wahab ${ }^{1,2^{*}}$, and Mariani Abdul Hamid ${ }^{3}$ \\ ${ }^{1}$ Department of Chemistry, Faculty of Science, Universiti Teknologi Malaysia, 81310 UTM Skudai, Johor, Malaysia \\ ${ }^{2}$ Enzyme Technology and Green Synthesis Group, Faculty of Science, Universiti Teknologi Malaysia, 81310 UTM Skudai, Johor, \\ Malaysia \\ ${ }^{3}$ School of Chemical and Energy Engineering, Faculty of Engineering, Universiti Teknologi Malaysia, 81310 Skudai, Johor, Malaysia
}

*Corresponding author:

email:roswanira@kimia.fs.utm.my

Received: June 3, 2020

Accepted: July 6, 2020

DOI: $10.22146 / \mathrm{ijc} .56587$

\begin{abstract}
The research was carried out to synthesize a stable kojic acid (KA) encapsulated nanoemulsion as a whitening agent for topical skin usage. In this study, the oil-in-water $(\mathrm{O} / \mathrm{W}) \mathrm{KA}$ nanoemulsion was formulated using integrated low and high energy methods that combined ultrasonic and hot temperature inversion methods. Several different combinations of parameters were screened, viz. xanthan gum amount (1.0 to $2.0 \mathrm{~g}$ ), kojic acid (KA) amount (0.5 to $1.5 \mathrm{~g}$ ), and surfactant-to-water ratio (1:10.75 to 1:4.875), to prepare a stable KA nanoemulsion. The identified best parameters to design the O/W KA nanoemulsion were then subjected to different stability tests: storage and $\mathrm{pH}$ stability (freeze-thaw and centrifugal tests). Results revealed that the Trial 6 formulation, with the highest ratio of Tween 80 to water $(1: 4.875 \mathrm{v} / \mathrm{v})$, yielded the best polydispersity index at $0.255 \pm 0.006$ with an average particle size of $90.57 \pm 1.401 \mathrm{~nm}$. The formulation retained the recommended $p H$ range ( $p H$ 4.95-5.18) for topical skin applications within six-week storage under room condition. The nanoemulsions were also kinetically stable as proven by the absence of phase separation after the centrifugation, freeze-thaw cycle, and storage temperature $\left(2\right.$ and $\left.25^{\circ} \mathrm{C}\right)$ tests, except at the $37^{\circ} \mathrm{C}$ threeweek extended storage. The results collectively showed that the formulated $\mathrm{O} / W \mathrm{KA}$ nanoemulsion is suitable for topical application on human skin.
\end{abstract}

Keywords: oil-in-water nanoemulsion; kojic acid; topical skin application; skin whitening; ultrasonic and hot temperature inversion methods

\section{- INTRODUCTION}

Melanogenesis is a complex physiological process controlled by both tyrosinase and tyrosinase-related protein-1 and -2 (TRP-1 and TRP-20) found in melanocytes, responsible for producing the melanin pigment. This natural pigment has an important role in protecting the human skin from injury due to sunlight while affording color to the skin and hair. However, melanin's over-production leads to aesthetic problems such as hyperpigmentation, wrinkling, melasma, and other dermatological disorders [1-2].

To inhibit skin pigmentation, 5-hydroxy-2hydroxymethyl-4H-pyran-4-one, commonly known as kojic acid (KA), is gaining popularity as an agent that inhibits melanin synthesis [3]. KA imparts its skin whitening effect by blocking ultraviolet radiation, suppressing hyperpigmentation, and preventing melanin formation by its tyrosinase inhibitory activity $[1,4-5]$. KA is also a widely used active ingredient in an array of cosmetics, medicines, foods, and agriculture and chemical industries due to its antibacterial, antimicrobial, antileukemic, and antifungal properties [6]. For KA to exhibit their depigmentation effect, a sufficient amount of this whitening agent should remain close to melanocytes for a stipulated duration. Such cells are typically located between the epidermis and dermis. One of the challenges for using $\mathrm{KA}$ as a hydrophilic 
active whitening agent is its poor penetration into the skin, and consequently, transportation to the target location. This is due to difficulties in KA to pass through the skin barrier that protects against ultraviolet light, pathogenic bacteria, and pollution. A hydrophobic active agent, on the other hand, is better adsorbed on the stratum corneum but is unable to penetrate deep into the skin due to the presence of water in the skin epidermis $[1,7]$.

Hence, surfactants and alcohols can be employed simultaneously to overcome such issues and enhance the transportation of KA through the human skin. In this research, sorbitan monooleate (Tween 80) was used as the surfactant to expedite the KA nanoemulsion formulation. Tween 80 also kinetically stabilizes the nanoemulsion for extended storage by minimizing the interfacial tension. The KA should also be encapsulated to improve the depigmentation effect by increasing the system's physicochemical stability, aside from preventing the general accumulation of whitening agents within the system $[1,8]$. This enhances the delivery of the active ingredient as diffusion issues through the stratum corneum barrier can be overcome, in turn, facilitating a higher presence of the active ingredient at the targeting area [9]. Encapsulated nanoparticles have a high surface area to volume ratio to effectively allow a controllable delivery of the active ingredient to targeted cells [10-11] and facilitate the transportation of hydrophilic molecules such as KA in the skin [12]. Besides that, the polymeric nanoparticles in the nanoemulsion system further stabilize the drug/active ingredients and boost the delivery of poorly soluble or poorly absorbed substances, alongside other chemicals, heat- and photo-labile components [13]. The nanoemulsions' small droplet size boosts the penetration of active ingredients, i.e., KA through the skin. This enhances their intended efficacies to reduce hyperpigmentation, wrinkling, melasma and other dermatological disorders, as well as promote a faster turnover cycle, and inhibition of melanosome transfer [14-15]. As far as we know, different forms of esterified kojic acid, viz. kojic dipalmitate and kojic monooleate were investigated as active ingredients in water/oil/water multiple emulsions and nanoemulsion, respectively [1617].

Cosmetic products with an active whitening agent such as KA are currently the topical skin whitening action choice. Hence, it makes sense that the potential of nanotechnology-based systems (DDS) to carry out encapsulation of the active whitening ingredient in nanoemulsion is investigated. To develop a kinetically stable topical oil-in-water $(\mathrm{O} / \mathrm{W})$ nanoemulsion using $\mathrm{KA}$ as the active ingredient, this study aimed to identify the best composition of xanthan gum amount, kojic acid (KA) amount, surfactant:water ratio in the formulation. Hence, this is the first-ever report that prepares a simplified, single surfactant (Tween 80) O/W KA nanoemulsion for topical delivery through an integrated ultrasonication and hot temperature technique. The turbulent micro-implosions from repeated acoustic bombardment during ultrasonication are highly effective in breaking up primary droplets of dispersed oil into droplets of sub-micron size.

In contrast, the hot temperature technique can flexibly tune the mixing temperature to achieve the nanodroplet quality in the O/W KA nanoemulsion [18]. The prepared O/W KA nanoemulsion was tested for stability in particle size and polydispersity index (PDI). In addition, tests were also carried out to determine the stability of the KA nanoemulsions in terms of storage and freeze-thaw stability and the system's $\mathrm{pH}$ stability for 6 weeks.

\section{- EXPERIMENTAL SECTION}

\section{Materials}

Xanthan gum from Xanthomonas campestris and kojic acid (KA) were purchased from Personal Formula Resources (Malaysia), while Tween 80 (polyoxyethylene sorbitan monooleate HLB = 15.0) were purchased from Scharlau (Barcelona, Spain). Grapeseed oil was procured from Aceies Borges Pont (Spain), and fragrance oil and phenoxyethanol (as preservative) were purchased from Luzi Fragrance Compounds (Johor, Malaysia), and Thor Specialty (US), respectively. All other chemicals were obtained from the General Chemistry Laboratory of 
Faculty of Science, Universiti Teknologi Malaysia, Malaysia.

\section{Instrumentation}

A $20 \mathrm{kHz}$ ultrasonic generator $(130 \mathrm{~W}, \mathrm{KH} 5200 \mathrm{DB}$ type, Kunshan ultrasonic instrument Co., Ltd., Jiangsu, China) was used to produce the coarse emulsion. HettichEBA20 (Germany) was used to create a centrifugal force (10,000 rpm, $10 \mathrm{~min})$ for the $\mathrm{O} / \mathrm{W}$ stability test. The KA nanoemulsion's $\mathrm{pH}$ stability was measured at $25^{\circ} \mathrm{C}$ using the Delta $320 \mathrm{pH}$ meter (Melter-Toledo, Schwerzenbach, Switzerland) after a 6-week incubation. Particle size and polydispersity index (PDI) were monitored using the Zetasizer Nano ZSP, Malvern Instrument, Malvern (UK).

\section{Procedure}

\section{Preparation and screening of formulation parameters for preparing $K A$ nanoemulsion}

In this research, an integrated ultrasonication and hot-temperature method were used to prepare the $\mathrm{O} / \mathrm{W}$ KA nanoemulsion. Firstly, grapeseed oil and Tween 80 (surfactant) were combined in a beaker to form the oil phase. In another beaker, the aqueous phase was prepared by mixing KA, xanthan gum, and deionized water under moderate stirring (100 rpm) for $5 \mathrm{~min}$. Both liquid phases were transferred to an oil bath and heated to $80^{\circ} \mathrm{C}$. Upon reaching the temperature, the liquids were removed from the heat. The oil phase was added dropwise into the aqueous phase under constant magnetic stirring at $600 \mathrm{rpm}$ for $10 \mathrm{~min}$, followed by the occasional manual stirring. Next, the coarse KA emulsion was transferred to an ice bath and ultrasonicated for 5 min to emulsify the mixture. Other components, for instance, fragrance and phenoxyethanol, were added dropwise during the ultrasonication process. For screening purposes, the above steps were repeated for another 6 sets to test for the varying amounts of xanthan gum, KA, surfactant to water ratio (Table 1). Lastly, the prepared KA nanoemulsions were transferred into screw-capped vials until further use.

\section{Particle size and PDI analysis}

It is important to note that PDI indicates homogeneity and stability, wherein the target range should be lower than 0.5 for a nanoemulsion. This value shows similar and narrow size distribution in the KA formulation, representing a more stable and uniformed nanoemulsion system [19]. For all cases, nanoparticles carrying encapsulated KA should be of sizes less than $100 \mathrm{~nm}$ to enable efficacious delivery of KA through the skin. In this study, all readings were taken at $25^{\circ} \mathrm{C}$ as temperature change can influence the stability of nanoemulsion, drug loading, and drug release [20].

Table 1. The different formulation parameters

\begin{tabular}{|c|c|c|c|c|c|c|c|c|c|c|c|c|c|c|}
\hline & \multicolumn{2}{|c|}{ Trial 1} & \multicolumn{2}{|c|}{ Trial 2} & \multicolumn{2}{|r|}{ Trial 3} & \multicolumn{2}{|c|}{ Trial 4} & \multicolumn{2}{|c|}{ Trial 5} & \multicolumn{2}{|c|}{ Trial 6} & \multicolumn{2}{|c|}{ Trial 7} \\
\hline Oil Phase & $\%$ & Amount & $\%$ & Amount & $\%$ & Amount & $\%$ & Amount & $\%$ & Amount & $\%$ & Amount & $\%$ & Amount \\
\hline Grapeseed Oil & 6 & $3 \mathrm{~mL}$ & 6 & $3 \mathrm{~mL}$ & 6 & $3 \mathrm{~mL}$ & 6 & $3 \mathrm{~mL}$ & 6 & $3 \mathrm{~mL}$ & 6 & $3 \mathrm{~mL}$ & $3 \mathrm{~mL}$ & 6 \\
\hline Tween 80 & 12 & $6 \mathrm{~mL}$ & 12 & $6 \mathrm{~mL}$ & 12 & $6 \mathrm{~mL}$ & 12 & $6 \mathrm{~mL}$ & 12 & $6 \mathrm{~mL}$ & 16 & $8 \mathrm{~mL}$ & $6 \mathrm{~mL}$ & 16 \\
\hline Aqueous Phase & $\%$ & Amount & $\%$ & Amount & $\%$ & Amount & $\%$ & Amount & $\%$ & Amount & $\%$ & Amount & $\%$ & Amount \\
\hline $\mathrm{H}_{2} \mathrm{O}$ & 82 & $41 \mathrm{~mL}$ & 82 & $41 \mathrm{~mL}$ & 82 & $41 \mathrm{~mL}$ & 82 & $41 \mathrm{~mL}$ & 82 & $41 \mathrm{~mL}$ & 78 & $39 \mathrm{~mL}$ & 86 & $43 \mathrm{~mL}$ \\
\hline Kojic Acid & - & $0.5 \mathrm{~g}$ & - & $1.0 \mathrm{~g}$ & - & $1.5 \mathrm{~g}$ & - & $1.0 \mathrm{~g}$ & - & $1.0 \mathrm{~g}$ & - & $1.0 \mathrm{~g}$ & - & $1.0 \mathrm{~g}$ \\
\hline Xanthan Gum & - & $1.5 \mathrm{~g}$ & - & $1.5 \mathrm{~g}$ & - & $1.5 \mathrm{~g}$ & - & $1.0 \mathrm{~g}$ & - & $2.0 \mathrm{~g}$ & - & $1.5 \mathrm{~g}$ & - & $1.5 \mathrm{~g}$ \\
\hline Additives & $\%$ & Amount & $\%$ & Amount & $\%$ & Amount & $\%$ & Amount & $\%$ & Amount & $\%$ & Amount & $\%$ & Amount \\
\hline Phenoxyethanol & - & $500 \mu \mathrm{L}$ & - & $500 \mu \mathrm{L}$ & - & $500 \mu \mathrm{L}$ & - & $500 \mu \mathrm{L}$ & - & $500 \mu \mathrm{L}$ & - & $500 \mu \mathrm{L}$ & - & $500 \mu \mathrm{L}$ \\
\hline Perfume & - & $20 \mu \mathrm{L}$ & - & $20 \mu \mathrm{L}$ & - & $20 \mu \mathrm{L}$ & - & $20 \mu \mathrm{L}$ & - & $20 \mu \mathrm{L}$ & - & $20 \mu \mathrm{L}$ & - & $20 \mu \mathrm{L}$ \\
\hline Total & 100 & $50 \mathrm{~mL}$ & 100 & $50 \mathrm{~mL}$ & 100 & $50 \mathrm{~mL}$ & 100 & $50 \mathrm{~mL}$ & 100 & $50 \mathrm{~mL}$ & 100 & $50 \mathrm{~mL}$ & 100 & $50 \mathrm{~mL}$ \\
\hline
\end{tabular}

Trial 1: Kojic Acid amount (lowest), Trial 2: Kojic Acid amount (moderate), Xanthan gum, amount (moderate), Surfactant to water ratio (moderate), Trial 3: Kojic Acid amount (highest), Trial 4: Xanthan gum amount (lowest), Trial 5: Xanthan gum amount (highest), Trial 6: Surfactant to water ratio (highest), Trial 7: Surfactant to water ratio (lowest) 


\section{Stability test}

In this study, stability tests on the formulated KA nanoemulsion were done to provide reasonable assurance that the product remains at an acceptable level of fitness or quality over different conditions. This study's stability tests were simulated under conditions that are likely to destabilize the KA nanoemulsion over time. The tests of the KA nanoemulsions included accelerated storage stability under centrifugal force, freeze-thaw cycles, as well as under conditions of high heat and cold. To enable comparison, each sample's initial conditions, such as appearance, color, fragrance, $\mathrm{pH}$, and viscosity, were recorded before each test [21-22].

For the storage stability test, triplicates of the KA nanoemulsion were subjected to variable temperatures ( 2 , $25,37^{\circ} \mathrm{C}$ ). This second test specifically observes the stability of the KA nanoemulsion under an accelerated destabilizing condition, i.e., centrifugal force $(10,000 \mathrm{rpm}$, $10 \mathrm{~min})$. It is worth indicating here that a correctly formulated KA nanoemulsion is stable under the previous tests and capable of resisting phase separation that transforms the system back into its individual components [21].

Next, the freeze-thaw stability test was conducted by subjecting each sample to a triply repeated cycle of freezing and thawing. Each condition was maintained for $24 \mathrm{~h}$ before the condition was changed. The physical appearance of an adequately stable KA nanoemulsion post-evaluation test should be similar to the pre-evaluated one and without any phase separation [21]. The $\mathrm{pH}$ stability of the KA nanoemulsion was then measured at $25{ }^{\circ} \mathrm{C}$ after a 6-week incubation.

\section{- RESULTS AND DISCUSSION}

\section{The rationale of the Preparation of Encapsulated Kojic Acid (KA) Nanoemulsion}

Literature has shown that the optimum $\mathrm{pH}$ range for topical nanoemulsions should closely resemble the $\mathrm{pH}$ of the surface of healthy human skin, which typically ranges between $\mathrm{pH}$ 4.0-6.0 [23-24]. However, a condition for better hydration is $\mathrm{pH}<5.0$ compared to skin with $\mathrm{pH}>$ 5.0. Conversely, a higher $\mathrm{pH}$ on the skin surface tends to intensify itching and skin dryness [22-23]. Thus, a slightly acidic skin surface protects against a myriad of invading microorganisms and offers better resistance against SLS-induced irritant dermatitis [25]. For these reasons, the formulated KA nanoemulsion was kept within the recommended $\mathrm{pH}$ range for healthy skin.

In this research, ultrasonic and hot temperature methods were used to prepare a stable oil-in-water $(\mathrm{O} / \mathrm{W})$ nanoemulsion containing encapsulated $\mathrm{KA}$. It is important to indicate here that the preparation of KA nanoemulsions required two separate phases involving the oil phase and aqueous phase. The components of the oil phase used in this study comprised grapeseed oil and Tween 80 . The study used grapeseed seed oil as the oil phase due to its high antioxidant content and anti-aging properties [26]. Moreover, grapeseed oil contains antioxidants, which include vitamin $\mathrm{E}$ and oligomeric proanthocyanidins. These components help reduce wrinkles by repairing collagen damaged by free radicals, moisturizing the skin, and enhancing skin elasticity [22]. The bulk physicochemical characteristics of the oil phase, for example, viscosity, are also important factors when preparing stable nanoemulsions. They can limit the type of homogenization method(s) preparing a nanoemulsion from a given oil phase. To be specific, the higher viscosity of grapeseed oil is crucial during the ultrasonication (high-energy method) is useful for the disruption of oil droplets into sub-micron size [18]. This enables the nanoemulsion to have a longer shelf-life as the creaming rate is decreased [27].

Another factor of concern when preparing the $\mathrm{O} / \mathrm{W}$ KA nanoemulsion is the suitability of Tween 80 for the KA encapsulation process to yield nanoparticle sizes of below $100 \mathrm{~nm}$ [20]. In this study, the non-ionic Tween 80 was chosen due to its low irritation and low toxicity, high surface activity even at a low concentration, and suitable for nanoemulsions prepared via both highenergy and low-energy methods [27-30]. Whereas the Hydrophilic Lipid Balance (HLB) value of 15 of Tween 80 stabilizes the $\mathrm{O} / \mathrm{W}$ KA nanoemulsions by increasing the affinity between the interacting molecules and lowers the interfacial tension between the water and KA in the oil phase. It also changes the interfacial layer's optimum curvature and increases the repulsive 
interactions (steric or electrostatic) between droplets [31]. Thus, the nanoemulsion system has higher stability, formulating flexibility, and wider compatibility [32]. Thus, the use of Tween 80 is popular in the cosmetic, pharmaceutical, and food industries.

Meanwhile, xanthan gum, KA, and distilled water formed the aqueous phase components since the innocuous, non-irritating, and non-sensitizing properties [33] of xanthan gum can stabilize the $\mathrm{O} / \mathrm{W}$ nanoemulsion. The system also contributes to the electrostatic and steric effects that repel similarly charged emulsion droplets. The condition sustains the bulky stabilizing layer barrier that maintains the kinetic stability of $\mathrm{O} / \mathrm{W}$ emulsions [34]. The high molecular weight and high viscosity of Tween 80 also promote a low shear rate that effectively decreases nanoparticle aggregation and enhances nanoemulsion stability [14]. Meanwhile, KA was chosen as the study's whitening agent due to its ability to inhibit tyrosinase activity and exhibit anti-oxidizing, anti-proliferative, anti-inflammatory, alongside radioprotective tendencies [6].

\section{Characterization of Encapsulated KA Nanoemulsion}

\section{Determination of particle size and polydispersity index (PDI)}

In this study, all prepared KA nanoemulsions were found to satisfy the required nanosize and data for particle sizes and PDIs for all formulations (Fig. 1). It is important to note that all the KA nanoemulsions were characterized within $24 \mathrm{~h}$ after preparation to ensure consistency of measurements. Rapid characterization is required because the structural organization of the KA nanoemulsion, alongside its composition and physicochemical properties, can fluctuate over time and space when there is a mix of the organic and aqueous phases [35]. Results revealed that KA nanoemulsions showed the presence of KA droplets with diameters ranging between $10-100 \mathrm{~nm}$ [20], as well as a welldistributed nanoparticle showing an average PDI of less than 0.5 [19]. The findings conveyed that the O/W KA nanoemulsions were well-formulated and appeared uniform in terms of size distribution. The narrow size distribution is seen in this study (PDI $=0.5$ ) effectively illustrated the successful preparation of a stable and uniformed nanoemulsion system [19], where Trial 6 formulation showed the highest ratio of Tween 80 to water $(1: 4.875 \mathrm{v} / \mathrm{v})$. The best PDI was $0.255 \pm 0.006$ with an average size of $90.57 \pm 1.401 \mathrm{~nm}$.

It is important to mention here that currently, cosmeceutical products formulated with smaller droplet sizes are trending among consumers, as the system supports a better permeation of the bioactive ingredient, i.e., KA through the stratum corneum. The minute size of KA particles seen in this study was the likelihood of the unsaturated non-polar tails of Tween 80 that facilitated an ideal packing of the surfactant molecules. This state essentially allowed the ultrafine droplets to form at the oil-water boundary freely [35]. Another study reported that an optimal ratio of the effective cross-sectional areas of the Tween 80 hydrophobic tail

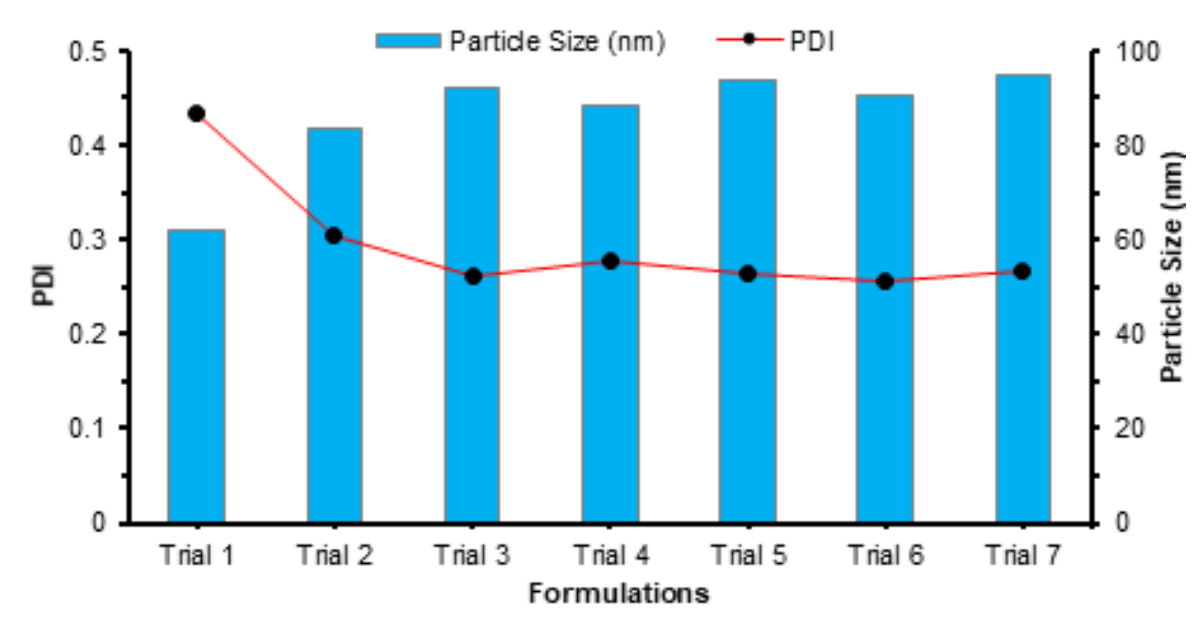

Fig 1. Graph of particle sizes and PDI for all seven trials 
part and its hydrophilic head part can synergistically and exclusively influence the surfactant's molecular geometry.

Based on the desirable small droplet size (90.57 \pm $1.401 \mathrm{~nm})$ and the satisfactory PDI $(0.255 \pm 0.006)$ of the KA nanoemulsion, it was clear that the formulation in Trial 6 resulted in an optimal ratio of Tween 80 to water. The formulation allowed the adoption of an optimum curvature of surfactants surrounding the KA particles during spontaneous emulsification. This phenomenon occurs due to the kinked nature of the unsaturated nonpolar tails of Tween 80, which have been irrefutably shown to promote a more 'curved' packing of the surfactant molecules over the oil-water interface [14]. As a matter of fact, several studies have achieved smaller droplet sizes when using non-polar chains of non-ionic unsaturated surfactants with more double bonds as the emulsifier in spontaneously formed nanoemulsions [3637]. At smaller particle sizes, the effect of Brownian motion is dominant over gravitational force, thus giving better emulsion stability [14]. The graph of particle size and PDI for all the trials are also shown in Fig. 1.

\section{Thermodynamic stability test}

In this investigation, the thermodynamic stability tests' phases consist of three components: centrifugation study, freeze-thaw cycle, and storage stability. As can be seen, all seven KA formulations were stable, and no phase separations were observed after centrifugation. This particular test allows the user to anticipate the destabilization of the prepared nanoemulsions through the creaming or coalescence of the dispersed phase. This test is also useful for predicting the prepared KA nanoemulsions' shelf life under storage normal conditions [38]. This study believed that differences in density of the oil and aqueous phase could have played a role in stabilizing the KA nanoemulsion. The findings also communicated normally distributed components in the nanoemulsion system [39].

The freeze-thaw cycle test was done in three replicates for temperatures $-10{ }^{\circ} \mathrm{C}$ (in the freezer), followed at room temperature $\left( \pm 25^{\circ} \mathrm{C}\right)$ at $24 \mathrm{~h}$ intervals. The test was triplicated, and the results are tabulated in Table 2 . The noteworthy absence of phase separation in all tested samples affirmed the stability of the nanoemulsion system. The O/W KA nanoemulsion stability was assisted by the bulky hydrophilic head groups of the incorporated Tween 80 that acted as a stearic barrier at the oil/water interface. This molecular arrangement prohibited the destabilization of the oil phase KA droplets by coalescence. It also averted collisions between the droplets, as similarly reported by other studies [40-41]. The additional presence of xanthan gum in the aqueous phase further precluded the movement of dispersed KA droplets and further stabilized the O/W nanoemulsion. Sriprablom et al. [34]

Table 2. Thermostability test results on phase separation for Trial 1-7

\begin{tabular}{|c|c|c|c|c|c|c|c|c|c|}
\hline \multicolumn{3}{|c|}{ Trials } & 1 & 2 & 3 & 4 & 5 & 6 & 7 \\
\hline \multirow{6}{*}{\multicolumn{2}{|c|}{ Centrifugation }} & Week 1 & $x$ & $x$ & $x$ & $x$ & $x$ & $x$ & $x$ \\
\hline & & Week 2 & $x$ & $x$ & $x$ & $x$ & $x$ & $x$ & $x$ \\
\hline & & Week 3 & $\times$ & $x$ & $x$ & $x$ & $x$ & $x$ & $x$ \\
\hline & & Week 4 & $x$ & $x$ & $x$ & $x$ & $x$ & $x$ & $x$ \\
\hline & & Week 5 & $x$ & $x$ & $x$ & $x$ & $x$ & $x$ & $x$ \\
\hline & & Week 6 & $x$ & $\times$ & $x$ & $\times$ & $\times$ & $x$ & $x$ \\
\hline \multirow{6}{*}{\multicolumn{2}{|c|}{$\begin{array}{c}\text { Freeze-Thaw } \\
\text { Cycle Test }\end{array}$}} & Week 1 & $x$ & $x$ & $x$ & $x$ & $x$ & $x$ & $x$ \\
\hline & & Week 2 & $x$ & $\times$ & $x$ & $\times$ & $x$ & $\times$ & $x$ \\
\hline & & Week 3 & $x$ & $\times$ & $x$ & $x$ & $x$ & $\times$ & $x$ \\
\hline & & Week 4 & $x$ & $\times$ & $x$ & $x$ & $x$ & $x$ & $x$ \\
\hline & & Week 5 & $x$ & $x$ & $x$ & $x$ & $x$ & $\times$ & $x$ \\
\hline & & Week 6 & $x$ & $\times$ & $x$ & $x$ & $x$ & $\times$ & $x$ \\
\hline \multirow{6}{*}{\multicolumn{2}{|c|}{$2^{\circ} \mathrm{C}$}} & Week 1 & $x$ & $x$ & $x$ & $x$ & $x$ & $x$ & $x$ \\
\hline & & Week 2 & $x$ & $x$ & $x$ & $x$ & $x$ & $\times$ & $x$ \\
\hline & & Week 3 & $x$ & $x$ & $x$ & $x$ & $x$ & $x$ & $x$ \\
\hline & & Week 4 & $x$ & $x$ & $x$ & $x$ & $x$ & $x$ & $x$ \\
\hline & & Week 5 & $x$ & $x$ & $x$ & $x$ & $x$ & $\times$ & $x$ \\
\hline & & Week 6 & $x$ & $\times$ & $x$ & $x$ & $x$ & $x$ & $x$ \\
\hline \multirow{12}{*}{$\begin{array}{l}\text { Storage } \\
\text { Stability }\end{array}$} & \multirow{6}{*}{$25^{\circ} \mathrm{C}$} & Week 1 & $x$ & $x$ & $x$ & $x$ & $x$ & $x$ & $x$ \\
\hline & & Week 2 & $\times$ & $x$ & $x$ & $x$ & $x$ & $\times$ & $x$ \\
\hline & & Week 3 & $x$ & $\times$ & $x$ & $x$ & $x$ & $\times$ & $x$ \\
\hline & & Week 4 & $x$ & $x$ & $x$ & $x$ & $x$ & $\times$ & $x$ \\
\hline & & Week 5 & $x$ & $x$ & $x$ & $x$ & $x$ & $x$ & $x$ \\
\hline & & Week 6 & $x$ & $x$ & $x$ & $x$ & $x$ & $x$ & $x$ \\
\hline & \multirow{6}{*}{$37^{\circ} \mathrm{C}$} & Week 1 & $x$ & $x$ & $x$ & $x$ & $x$ & $x$ & $x$ \\
\hline & & Week 2 & $\times$ & $x$ & $x$ & $x$ & $x$ & $x$ & $x$ \\
\hline & & Week 3 & $x$ & $\times$ & $x$ & $x$ & $x$ & $x$ & $x$ \\
\hline & & Week 4 & $\sqrt{ }$ & $\sqrt{ }$ & $\sqrt{ }$ & $\sqrt{ }$ & $\sqrt{ }$ & $\sqrt{ }$ & $\sqrt{ }$ \\
\hline & & Week 5 & $\sqrt{ }$ & $\sqrt{ }$ & $\sqrt{ }$ & $\sqrt{ }$ & $\sqrt{ }$ & $\sqrt{ }$ & $\sqrt{ }$ \\
\hline & & Week 6 & $\sqrt{ }$ & $\sqrt{ }$ & $\sqrt{ }$ & $\sqrt{ }$ & $\sqrt{ }$ & $\sqrt{ }$ & $\sqrt{ }$ \\
\hline
\end{tabular}

$x=$ No phase separation occurs; $\sqrt{ }=$ Phase separation occurs 
also reported a comparable outcome when they incorporated xanthan gum in the aqueous phase of whey protein stabilized O/W emulsions. The reason behind this is the presence of shear-thinning high molecular weight polymers that encourages the formation of a high viscosity nanoemulsion at low shear rates, thereby decreasing the likelihood of a destabilized continuous phase [14].

Results for the storage stability, on the one hand, showed that all formulated emulsions placed under different temperatures $\left(2,25,37^{\circ} \mathrm{C}\right)$, remained stable and phase separation was not observed in the first three weeks. The tested KA nanoemulsions for the stability tests are shown in Fig. 2(a-e). Again, the study's observation supported the stability of the KA nanoemulsions under varying storage conditions and extended storage duration. All KA nanoemulsions samples subjected to extended storage at the lowest temperature $\left(2{ }^{\circ} \mathrm{C}\right)$ appeared whiter in color due to the gelation process [31].

On the other hand, all KA formulations were notably more yellowish when stored at the highest tested temperature $\left(37^{\circ} \mathrm{C}\right)$ after three weeks. This outcome was caused by an increase in the growth rate of KA droplets in the system due to coalescence. This was somewhat expected as the issue typically affects $\mathrm{O} / \mathrm{W}$ nanoemulsions stored at higher temperatures [31], particularly when a thermal sensitive non-ionic surfactant is used in the formulation [19]. The study believed that the thermal sensitive nature of Tween 80 was to blame for the more rapid destabilization of the $\mathrm{O} / \mathrm{W}$ KA nanoemulsion stored at $37^{\circ} \mathrm{C}$. Hence, the formulations produced here were not suitable for storage at temperatures exceeding $30{ }^{\circ} \mathrm{C}$ (Table 2).

\section{pH Stability over an Extended Storage Period}

It is important to highlight here, the optimum $\mathrm{pH}$ range for a topical application of a nanoemulsion should be close to the $\mathrm{pH}$ of natural healthy human skin ( $\mathrm{pH}$ 4.06.0) [20] to maintain good hydration and protect against invading microorganisms [23]. In this research, the $\mathrm{pH}$ of formulated $\mathrm{O} / \mathrm{W}$ nanoemulsions was determined weekly for six weeks, and they were found to range between $\mathrm{pH}$ 4.66 to 5.55 . All formulations generally showed a decreasing (a)

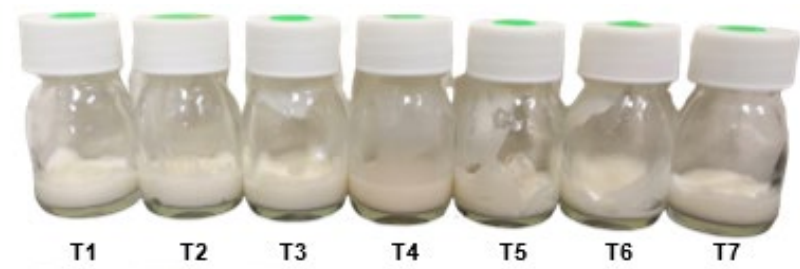

(b)

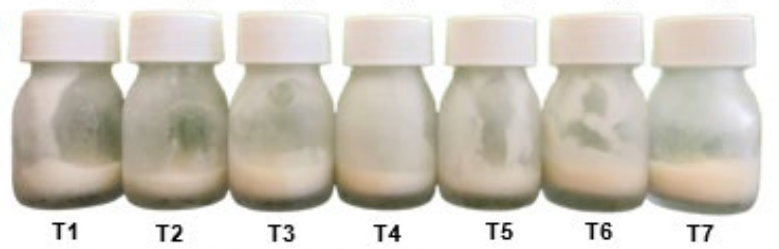

(c)

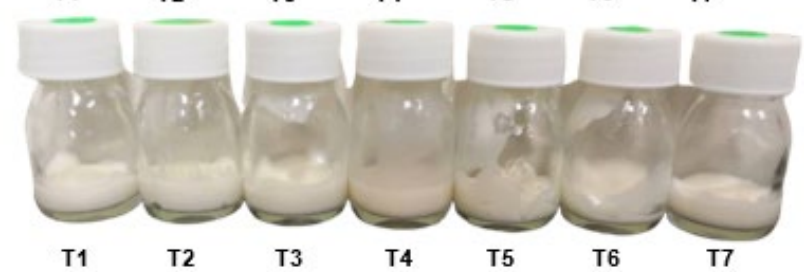

(d)

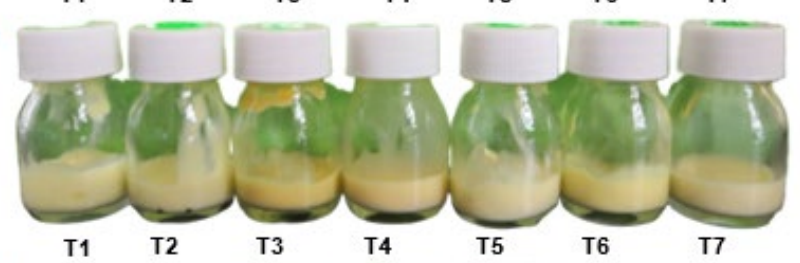

(e)

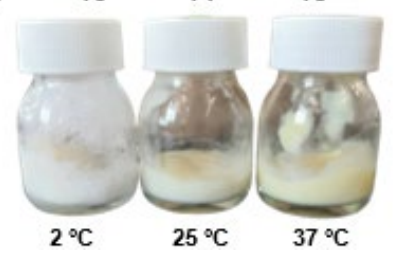

Fig 2. The appearance of Formulations 1-7 after the (a) freeze-thaw cycle test, (b) extended storage at $2{ }^{\circ} \mathrm{C}$ after 6 weeks, (c) storage at $25^{\circ} \mathrm{C}$ after 6 weeks and (d) storage at $37^{\circ} \mathrm{C}$ after 6 weeks (e) Formulations of Trial 6 (best formulation) stored under different temperatures $(2,25$, $37^{\circ} \mathrm{C}$ ) after 6 weeks

trend in terms of $\mathrm{pH}$ value from week 1 to week 6 . This can be attributed to the presence of free fatty acids liberated by the degradation of the oil phase components or the hydrolysis process caused by the temperature factor [14].

The outcome of this study corroborated the likelihood that the O/W KA nanoemulsions had undergone oxidation under the high storage temperature. Literature has shown that high temperatures tend to promote the release of a higher concentration of free hydrogen ions, which lowers a system's $\mathrm{pH}$. In the case of 


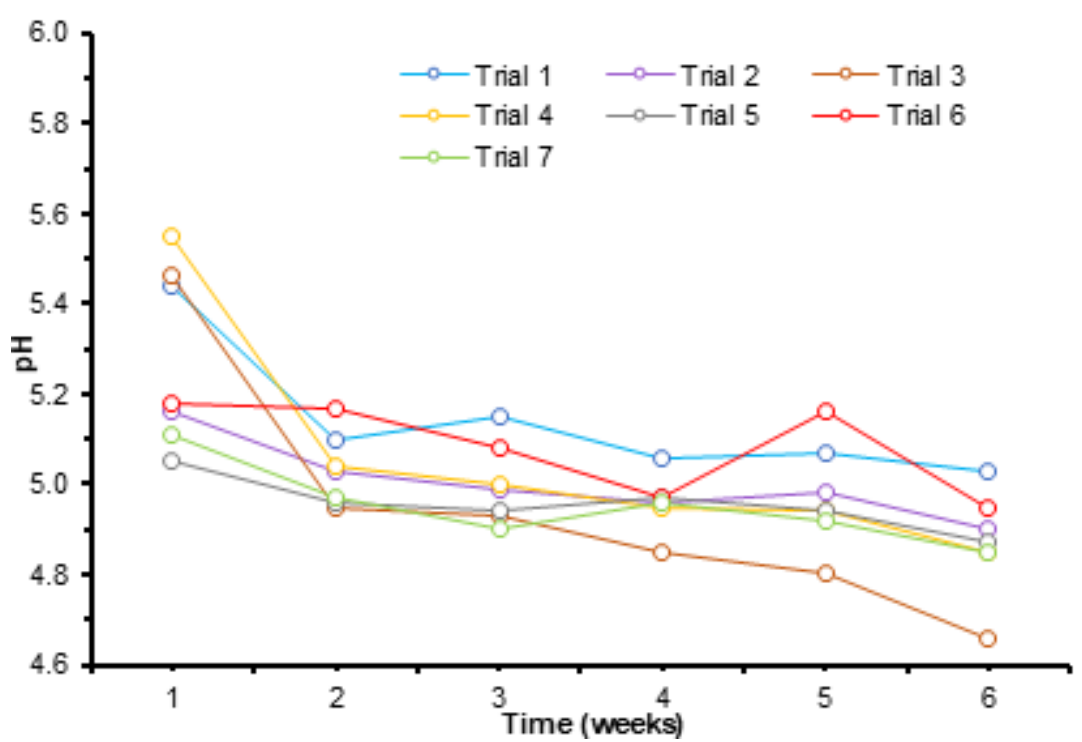

Fig 3. Graph of $\mathrm{pH}$ values for Trial 1-7 over 6 weeks

this study, the destabilizing factor of a reduced $\mathrm{pH}$ in the KA nanoemulsion has to be the surplus of hydrogen ions. These ions counteracted the negatively charged ions and undesirably reduced the zeta potential. This accelerated flocculation within the O/W system [42]. However, all KA formulations' $\mathrm{pH}$ values observably remained within the ideal range of the skin $\mathrm{pH}$ (between 4-6), thus indicating their stability [14]. In conclusion, the results demonstrated that the formulated KA nanoemulsions are within the suggested $\mathrm{pH}$ range and suitable for topical applications on human skin. The trend of $\mathrm{pH}$ value over six weeks observed in this study is illustrated in Fig. 3.

\section{- CONCLUSION}

In this study, the nanoemulsion containing KA screening was done successfully to prepare by a combined treatment of ultrasonication and hot-temperature methods. The study discovered that the Trial 6 formulation with the highest ratio of Tween 80 to water $(1: 4.875 \mathrm{v} / \mathrm{v})$ yielded the best PDI at $0.255 \pm 0.006$, which corresponded to an average particle size of $90.57 \pm 1.401$ $\mathrm{nm}$. Trial 6 formulated KA nanoemulsion showed good storage capability under low temperature $\left(2^{\circ} \mathrm{C}\right)$ and room temperature $\left(25^{\circ} \mathrm{C}\right)$, as supported by the absence of phase separation. However, three weeks into storage at $37^{\circ} \mathrm{C}$, the KA nanoemulsion turned slightly yellowish, which signified the onset of phase separation. Thus, a review of parameters to prepare the nanoemulsion must be done to improve the storage stability at this temperature. The absence of phase separation after three consecutive freeze-thaw cycles and centrifugal tests affirmed the kinetically stable KA nanoemulsions, as their $\mathrm{pH}$ remained within the recommended $\mathrm{pH}$ range of $\mathrm{pH} 4.95$ to 5.18 for 6 weeks storage. The results collectively thus, supported the continued suitability of the KA emulsion for topical human skin applications.

\section{- ACKNOWLEDGMENTS}

This work was supported by the Fundamental Research Grant Scheme (QJ130000.2526.17H48) from the Ministry of Higher Education.

\section{- REFERENCES}

[1] Ha, J.H., Jeong, Y.J., Kim, A.Y., Hong, I.K., Lee, N.H., and Park, S.N., 2018, Preparation and Physicochemical properties of a cysteine derivativeLoaded deformable liposomes in hydrogel for enhancing whitening effects, Eur. J. Lipid Sci. Technol., 120 (9), 1800125.

[2] Zhou, J., Ren, T., Li, Y., Cheng, A., Xie, W., Xu, L., Peng, L., Lin, J., Lian, L., Diao, Y., Jin, X., and Yang, L., 2017, Oleoylethanolamide inhibits $\alpha$ melanocyte stimulating hormone-stimulated melanogenesis via ERK, Akt and CREB signaling 
pathways in B16 melanoma cells, Oncotarget, 8 (34), 56868-56879.

[3] Seino, H., Arai, Y., Nagao, N., Ozawa, N., and Hamada, K., 2016, Efficient percutaneous delivery of the antimelanogenic agent glabridin using cationic amphiphilic chitosan micelles, PloS One, 11 (10), e0164061.

[4] Hseu, Y.C., Cheng, K.C., Lin, Y.C., Chen, C.Y., Chou, H.Y., Ma, D.L., Leung, C.H., Wen, Z.H., and Wang, H.M.D., 2015, Synergistic effects of linderanolide B combined with arbutin, PTU or kojic acid on tyrosinase inhibition, Curr. Pharm. Biotechnol., 16 (12), 1120-1126.

[5] Wang, X.R., Cheng, H.M., Gao, X.W., Zhou, W., Li, S.J., Cao, X.L., and Yan, D., 2019, Intercalation assembly of kojic acid into $\mathrm{Zn}$-Ti layered double hydroxide with antibacterial and whitening performances, Chin. Chem. Lett., 30 (4), 919-923.

[6] Saeedi, M., Eslamifar, M., and Khezri, K., 2019, Kojic acid applications in cosmetic and pharmaceutical preparations, Biomed. Pharmacother., 110, 582-593.

[7] Parvez, S., Kang, M., Chung, H.S., Cho, C., Hong, M.C., Shin, M.K., and Bae, H., 2006, Survey and mechanism of skin depigmenting and lightening agents, Phytother. Res., 20 (11), 921-934.

[8] Ephrem, E., Elaissari, H., and Greige-Gerges, H., 2017, Improvement of skin whitening agents efficiency through encapsulation: Current state of knowledge, Int. J. Pharm., 526 (1-2), 50-68.

[9] Zhu, L.F., Zheng, Y., Fan, J., Yao, Y., Ahmad, Z., and Chang, M.W., 2019, A novel core-shell nanofiber drug delivery system intended for the synergistic treatment of melanoma, Eur. J. Pharm. Sci., 137, 105002.

[10] Calixto, G.M.F., de Annunzio, S.R., Victorelli, F.D., Frade, M.L., Ferreira, P.S., Chorilli, M., and Fontana, C.R., 2019, Chitosan-based drug delivery systems for optimization of photodynamic therapy: A review, AAPS PharmSciTech, 20 (7), 253.

[11] Mondal, S., Hoang, G., Manivasagan, P., Kim, H., and Oh, J., 2019, Nanostructured hollow hydroxyapatite fabrication by carbon templating for enhanced drug delivery and biomedical applications, Ceram. Int., 45 (14), 17081-17093.

[12] Anirudhan, T., and Nair, S.S., 2019, Development of voltage gated transdermal drug delivery platform to impose synergistic enhancement in skin permeation using electroporation and gold nanoparticle, Mater. Sci. Eng., C, 102, 437-446.

[13] Bangun, H., Tandiono, S., and Arianto, A., 2018, Preparation and evaluation of chitosantripolyphosphate nanoparticles suspension as an antibacterial agent, J. Appl. Pharm. Sci., 8 (12), 147156.

[14] Ribeiro, R.C.A., Barreto, S.M.A., Ostrosky, E.A., da Rocha-Filho, P.A., Verissimo, L.M., and Ferrari, M., 2015, Production and characterization of cosmetic nanoemulsions containing Opuntia ficus-indica (L.) mill extract as moisturizing agent, Molecules, 20 (2), 2492-2509.

[15] Sung, H.J., Khan, M.F., and Kim, Y.H., 2019, Recombinant lignin peroxidase-catalyzed decolorization of melanin using in-situ generated $\mathrm{H}_{2} \mathrm{O}_{2}$ for application in whitening cosmetics, Int. J. Biol. Macromol., 136, 20-26.

[16] Roselan, M.A., Ashari, S.E., Faujan, N.H., Mohd Faudzi, S.M., and Mohamad, R., 2020, An Improved nanoemulsion formulation containing kojic monooleate: Optimization, characterization and in vitro studies, Molecules, 25 (11), 2616.

[17] Gonçalez, M.L., Marcussi, D.G., Calixto, G.M.F., Corrêa, M.A., and Chorilli, M., 2015, Structural characterization and in vitro antioxidant activity of kojic dipalmitate loaded W/O/W multiple emulsions intended for skin disorders, Biomed Res. Int., 2015, 304591.

[18] Che Marzuki, N.H., Wahab, R.A., and Abdul Hamid, M., 2019, An overview of nanoemulsion: Concepts of development and cosmeceutical applications, Biotechnol. Biotechnol. Equip., 33 (1), 779-797.

[19] Mohd Narawi, M., Chiu, H.I., Yong, Y.K., Mohamad Zain, N.N., Ramachandran, M.R., Tham, C.L., Samsurrijal, S.F., and Lim, V., 2020, 
Biocompatible nutmeg oil-loaded nanoemulsion as phyto-repellent, Front. Pharmacol., 11, 214.

[20] Aboofazeli, R., 2010, Nanometric-scaled emulsions (nanoemulsions), Iran. J. Pharm. Res., 9 (4), 325-326.

[21] Ali, M.S., Alam, M.S., Alam, N., and Siddiqui, M.R., 2014, Preparation, characterization and stability study of dutasteride loaded nanoemulsion for treatment of benign prostatic hypertrophy, Iran. J. Pharm. Res., 13 (4), 1125-1140.

[22] Sumaiyah, and Leisyah, B.M., 2019, The effect of antioxidant of grapeseed oil as skin anti-aging in nanoemulsion and emulsion preparations, Rasayan J. Chem., 12 (13), 1185-1194.

[23] Ali, S.M., and Yosipovitch, G., 2013, Skin pH: From basic science to basic skin care, Acta Derm. Venereol., 93 (3), 261-267.

[24] Panther, D.J., and Jacob, S.E., 2015, The importance of acidification in atopic eczema: an underexplored avenue for treatment, J. Clin. Med., 4 (5), 970-978.

[25] Lambers, H., Piessens, S., Bloem, A., Pronk, H., and Finkel, P., 2006, Natural skin surface $\mathrm{pH}$ is on average below 5, which is beneficial for its resident flora, Int. J. Cosmet. Sci., 28 (5), 359-370.

[26] Garavaglia, J., Markoski, M.M., Oliveira, A., and Marcadenti, A., 2016, Grape seed oil compounds: Biological and chemical actions for health, Nutr. Metab. Insights, 9, 59-64.

[27] McClements, D.J., and Rao, J., 2011, Food-grade nanoemulsions: Formulation, fabrication, properties, performance, biological fate, and potential toxicity, Crit. Rev. Food Sci. Nutr., 51 (4), 285-330.

[28] Pulce, C., and Descotes, J., 1996, "Household products" in Human Toxicology, $1^{\text {st }}$ Ed., Eds. Descotes, J., Elsevier Science B.V., Amsterdam, 683-702.

[29] Sharma, N., Mohanakrishnan, D., Sharma, U.K., Kumar, R., Richa, Sinha, A.K., and Sahal, D., 2014, Design, economical synthesis and antiplasmodial evaluation of vanillin derived allylated chalcones and their marked synergism with artemisinin against chloroquine resistant strains of Plasmodium falciparum, Eur. J. Med. Chem., 79, 350-368.

[30] Manning, M.C., Liu, J., Li, T., and Holcomb, R.E.,
2018, Rational design of liquid formulations of proteins, Adv. Protein Chem. Struct. Biol., 112, 1-59.

[31] Rao, J., and McClements, D.J., 2010, Stabilization of phase inversion temperature nanoemulsions by surfactant displacement, J. Agric. Food Chem., 58 (11), 7059-7066.

[32] Anuar, N., Mohd Adnan, A.F., Saat, N., Aziz, N., and Mat Taha, R., 2013, Optimization of extraction parameters by using response surface methodology, purification, and identification of anthocyanin pigments in Melastoma malabathricum fruit, Sci. World J., 2013, 810547.

[33] Kumar, A., Rao, K.M., and Han, S.S., 2018, Application of xanthan gum as polysaccharide in tissue engineering: A review, Carbohydr. Polym., $180,128-144$.

[34] Sriprablom, J., Luangpituksa, P., Wongkongkatep, J., Pongtharangkul, T., and Suphantharika, M., 2019. Influence of $\mathrm{pH}$ and ionic strength on the physical and rheological properties and stability of whey protein stabilized $\mathrm{O} / \mathrm{W}$ emulsions containing xanthan gum, J. Food Eng., 242, 141-152.

[35] Saberi, A.H., Fang, Y., and McClements, D.J., 2013, Fabrication of vitamin E-enriched nanoemulsions: Factors affecting particle size using spontaneous emulsification, J. Colloid Interface Sci., 391, 95-102.

[36] Nejadmansouri, M., Hosseini, S.M.H., Niakosari, M., Yousefi, G.H., and Golmakani, M.T., 2017, Changes in the surface tension and viscosity of fish oil nanoemulsions developed by sonication during storage, Iran. Food Sci. Technol. Res. J., 13 (6) 105116.

[37] Wang, L., Dong, J. Chen, J. Eastoe, J., and Li, X., 2009, Design and optimization of a new selfnanoemulsifying drug delivery system, J. Colloid. Interface. Sci., 330 (2), 443-448.

[38] Mat Hadzir, N., Basri, M., Abdul Rahman, M.B., Salleh, A.B., Raja Abdul Rahman, R.N., and Basri, H., 2013, Phase behaviour and formation of fatty acid esters nanoemulsions containing piroxicam, AAPS PharmSciTech, 14 (1), 456-463.

[39] El-Din, M.R.N., El-Hamouly, S.H., Mohamed, 
H.M., Mishrif, M.R., and Ragab, A.M., 2014, Investigating factors affecting water-in-diesel fuel nanoemulsions, J. Surfactants Deterg., 17 (4), 819-831.

[40] Chang, Y., McLandsborough, L., and McClements, D.J., 2015, Fabrication, stability and efficacy of dualcomponent antimicrobial nanoemulsions: Essential oil (thyme oil) and cationic surfactant (lauric arginate), Food Chem., 172, 298-304.

[41] Samson, S., Basri, M., Fard Masoumi, H.R., Abedi
Karjiban, R., and Abdul Malek, E., 2016, Design and development of a nanoemulsion system containing copper peptide by D-optimal mixture design and evaluation of its physicochemical properties, RSC Adv., 6 (22), 17845-17856.

[42] Suminar, M.M., and Jufri, M., 2017, Physical stability and antioxidant activity assay of a nanoemulsion gel formulation containing tocotrienol, Int. J. Appl. Pharm., 9, 140-143. 